\title{
Diseño del arte visual y animación digital de la plataforma educativa interactiva
}

\author{
Rodríguez Alanís, F.B. ${ }^{1}$, Dena Caldera, L.A, ${ }^{2}$ Garza Moya L.R. ${ }^{3}$ \\ ${ }^{1-2}$ Ing. en Animación y Efectos Visuales, ${ }^{3}$ Ing. en Tecnologías de la Información, \\ Universidad Politécnica de Gómez Palacio \\ Carretera El Vergel-La Torreña Km. 0 820, C.P. 35120, Localidad El Vergel, Gómez Palacio, Durango \\ México, TELÉFONO: (871) 192-2700. \\ ${ }^{1}$ frodriguez@upgop.edu.mx, ${ }^{2}$ adriandena@live.com, ${ }^{3}$ lgarza@upgop.edu.mx
}

Fecha de recepción: 6 de octubre 2015

Fecha de aceptación: 10 de diciembre 2015

\begin{abstract}
Resumen. En el siguiente documento se presenta el diseño de una plataforma educativa de herramientas y temas de salud para el ciudadano, realizado por la filial mexicana de la empresa Compax, la cual trabaja en proyectos de centros comunitarios digitales, para su conversión posterior en ciberescuelas. Con el objetivo de ser un elemento transformador de la sociedad ante un entorno cambiante, donde la aplicación de Tecnologías de la Información y la Comunicación (TIC) en la Educación, se presenta como una oportunidad para promover el aprendizaje y mejorar la enseñanza en el marco del desarrollo de comunidades de aprendizaje virtuales. En este contexto la animación digital juega un papel muy importante, al tener el poder de atrapar la atención de una persona, ayudando a generar interés en temas poco atractivos -como la prevención en la salud- así como ayudándole a entender ideas complejas más fácilmente.
\end{abstract}

Palabras Clave: E-learning, Animación Digital, Ambientes Virtuales de Aprendizaje, Comunidades de Aprendizaje, Internet, México.

Summary. The present document thus presents the design of an educational platform of tools and issues relating to the importance of health care to the common people, undertaken in the Mexican company Compax, which develops digital community centers projects, for the subsequent conversion into e-Schools. This for the purpose of being an active element in society, facing a rapidly changing environment where implementation of information and communications technologies in education presents itself as an opportunity for improving teaching and learning within the framework of virtual learning communities. In this context, Digital Animation plays a key role to catch the attention of the people, helping to generate interest on topics considered particularly neither attractive nor unattractive -such as public health prevention- therefore helping to understand ideas that are far more complex.

Keywords: E-learning, Digital Animation, Virtual Learning Environments, Learning Communities, Internet, México.

\section{Introducción. Contexto del proyecto.}

El presente documento narra el desarrollo de proyecto de una plataforma educativa interactiva para el sector público, llevado a cabo durante un proyecto de vinculación con la empresa Compax. Ideas y Tecnología, S.A. de C.V. y la Universidad Politécnica de Gómez Palacio (UPGOP).

Compax es una empresa mexicana que desarrolla proyectos de centros comunitarios digitales, los cuales se convirtieron en ciberescuelas enfocadas en llevar contenidos de aprendizaje al ciudadano, haciendo uso de tecnologías actuales. Esto con el objetivo de ser un elemento transformador de la sociedad.

La animación juega un papel importante en la educación, ya que tiene el poder de atrapar la atención de una persona, especialmente de alguien joven, durante mucho tiempo, ayudando a generar interés en temas y asignaturas usualmente catalogados como aburridos, "de rollo", "relleno", etc. Dicho interés es crucial en el proceso de aprendizaje, ya que sin él la concentración se vuelve difícil, incluso para un adulto. Después de todo, el ser humano es lúdico por naturaleza, ergo, al presentársele el conocimiento en la forma de juego o entretenimiento este responde de mejor manera, haciéndolo verdaderamente suyo, apropiándose del mismo, una situación lúdica en la que el alumno se vuelve parte del instructor, borrándose las fronteras didácticas entre uno y otro, quedando el maestro solo para evaluar o controlar procesos [1].Así pues, el empleo de la animación, efectos visuales y sonoros, como parte de los esfuerzos llevados a cabo con las Tecnologías de la Información y la Comunicación (TIC) en la educación puede ayudar al aprendiz a entender ideas complejas más fácilmente, siendo agentes motivadores del aprendizaje. [2][3]

Particularmente en este documento se encontrará el desarrollo del aspecto visual de una plataforma educativa de herramientas y temas de salud para el ciudadano, desarrollado para el sector público, sin embargo cabe aclarar que por acuerdo de confidencialidad no es posible mencionar directamente al cliente. Así mismo, se estudia la problemática, el planteo de la solución así como todos los aspectos necesarios para sentar la base del proyecto. Se estructura de forma general cómo se llevaron a cabo las actividades para lograr el objetivo. Por otra parte, se explican grosso modo los fundamentos teóricos de los conceptos aplicados en el desarrollo del proyecto, así como el proceso de diseño paso a paso desde la concepción de los bocetos hasta el resultado final. 
La última parte del documento comprende los resultados del estudio mercadológico, así como las conclusiones finales y recomendaciones para trabajos futuros.

Cabe resaltar que la industria de la animación como actividad económica y académica en México, se encuentra aún en desarrollo. Los primeros profesionistas puros están empezando a egresar de las universidades públicas y privadas. Antes de ellos, la actividad industrial como tal de esta, si bien existente e importante México ocupa después de todo un importante lugar en las industrias creativas en sectores con uso intensivo en tecnología, como cine, televisión, radio, animación digital y videojuegos [4]- estaba llevándose a cabo por personas egresadas de carreras solo marginalmente conectadas con la animación como tal: diseñadores gráficos, Ingenieros en sistemas computacionales e incluso comunicólogos, quienes han "aprendido el oficio de la animación y modelación" sobre la marcha. Sin embargo, tal y como se demuestra en el presente artículo, la llegada de profesionistas dedicadas exprofeso a esta actividad está transformándola gracias en gran medida a la implementación de un enfoque metodológico y sistémico, enseñado a ellos en el curso de su carrera, lo cual permite enfrentar proyectos como el aquí descrito de forma más eficiente.

\subsection{Tipo de Proyecto y objetivo general.}

El Desarrollo de animaciones y arte visual para la implementación de una plataforma educativa interactiva en línea que mejore la experiencia de los usuarios, desarrollada por la empresa Compax, ubicada en la Cd. de Torreón Coahuila, de Septiembre a Noviembre de 2014, para el sector público (el nombre del cliente final debe permanecer confidencial por acuerdo firmado) la cual tiene como "target" al ciudadano mexicano promedio. Esto mediante el diseño de animaciones y personajes que vuelvan al contenido más atractivo, procurando con ello que el aprendizaje llevado a cabo sea más eficiente.

\subsection{Objetivos específicos.}

Realizar la animación introductoria al software (pantalla splash), creación de personajes para contenidos, diseño de la mascota del software, diseño del logotipo de la aplicación, banco de imágenes y diseño de actividades interactivas.

\subsection{Problemática a resolver}

Atrapar la atención del usuario moderno se ha convertido en un reto en los últimos años. Es por ello que el aspecto visual de cualquier aplicación informática tiene un papel determinante en la experiencia que el usuario tiene con el producto. Para ello se hace uso de recursos multimedia como animaciones, audio y un estudio de la colorimetría adecuada. Actualmente vivimos en un mundo en que existen millones de aplicaciones para infinidad de usos, y aquellas que son más funcionales pero sobre todo lucen atractivas visualmente son las que predominan.

\subsection{Propuesta/ planteamiento}

Desarrollar recursos multimedia para incorporarlos a los diversos productos informáticos realizados por la empresa. Procurando crear una imagen amigable y atractiva, por lo cual se recurrirá al diseño de personajes caricaturizados y coloridos, ya que el enfoque es para todo público, desde infantil hasta adulto.

\subsection{Alcances.}

El proyecto consiste en una plataforma educativa para la promoción de diversos temas, como una vida saludable, competencias para la vida, entre otros, se pretende incorporar de forma piloto en las salas de cómputo en clínicas de la región, para luego implementarlo en diferentes hospitales de la república. Esto con la finalidad de que las personas que no cuentan con computadora personal puedan utilizarla desde otros dispositivos disponibles en empresas o instituciones, ya que esta plataforma tiene el formato de página web, por lo que puede ser ingresada en línea. 


\section{Metodología}

Debido a que este proyecto tiene un perfil de usuario final bastante amplio, es crucial hacer uso de todas las técnicas de animación posibles, de forma que el público más joven pueda también ser involucrado en los diversos temas didácticos. La metodología escogida es la estándar para el desarrollo de nuevos productos y que ha sido analizado y desagregado por diversos autores que describen la metodología que debe seguir una empresa para el diseño y lanzamiento de productos al mercado, basándose en la metodología propuesta por seis autores diferentes y mencionados por Ivañez [5], adaptándola esta nueva actividad como lo es el diseño y aplicación de mensajes audiovisuales en animación 2D y 3D aplicados al diseño de plataformas educativas. A continuación, los pasos que se llevaron a cabo para el desarrollo del proyecto:

\subsection{Investigación Preliminar: Orientación y preparación.}

Los requerimientos del proyecto son recibidos del Departamento de Desarrollo de Software, quienes conjuntamente con el cliente establecen los requisitos que habrá de cumplir el producto [5], se establece el tipo de proyecto a desarrollar, objetivos que deberá de cumplir, fijar tiempos para el desarrollo del mismo, preparar una propuesta inicial y delimitar los alcances del proyecto.

\subsection{Investigación Preliminar: Análisis del contexto y recogida de datos sobre el entorno del producto.}

Una vez redactada la propuesta inicial, se estudia el contexto social y cultural donde habrá de implementarse, así como información del usuario del producto, con la finalidad de identificar las posibles áreas de oportunidad o problemas previsibles. Con esta información de implementa un estudio de factibilidad de estableciendo las especificaciones esenciales del producto y analizando la viabilidad financiera [5].

\subsection{Fase de Diseño/ Fase Técnica creativa: Diseño del Producto.}

A partir de los atributos definidos de los objetivos y necesidades delimitadas del proyecto se procede a la conceptualización del mismo, realizando una serie de propuestas de solución a los requisitos que debe cumplir, desarrollando bocetos, produciendo prototipos, eligiendo así las más adecuadas, de tal forma que el producto final sea capaz de satisfacer las necesidades del cliente y por ende del consumidor final [5].

\section{Creación de personajes.}

a) Buscar referencias para la creación de personajes, como ropa o peinados.

b) Llevar a cabo bocetos y trabajarlos hasta al alcanzar el aspecto deseado.

c) Digitalizar los bocetos de manera vectorial en el programa denominado "Adobe illustrator".

d) Hacer correcciones mediante la retroalimentación recibida de los coordinadores de desarrollo.

e) Entregar las imágenes finales a los programadores para que puedan incrustarlas en el código del software.

\section{Diseño del logotipo y banco de imágenes.}

Trazar las formas de manera vectorial en Adobe illustrator.

b) Hacer correcciones mediante la retroalimentación recibida de los coordinadores de desarrollo.

c) Entregar las imágenes finales a los programadores para que puedan incrustarlas en el código del software.

\section{Diseño de mascota.}

a) Buscar referencias para la creación de personajes, como ropa o peinados.

b) Llevar a cabo bocetos y trabajarlos hasta al alcanzar el aspecto deseado.

c) Digitalizar los bocetos de manera vectorial en el software de animación digital 2D "Toon Boom".

d) Crear el esqueleto del personaje con la herramienta Joint e inverse kinematics.

e) Realizar la animación correspondiente con la herramienta LipSync.

f) Hacer correcciones mediante la retroalimentación recibida de los coordinadores de desarrollo.

g) Hacer el render final. 
Diseño pantalla "splash"

a) Diseñar los elementos que aparecerán en la composición de la pantalla splash e importarlos.

b) Realizar la animación correspondiente con ayuda de las curvas de animación en After Effects.

c) Hacer correcciones mediante la retroalimentación recibida de los coordinadores de desarrollo.

d) Hacer el render final.

\section{Diseño de actividades interactivas en Adobe Flash y Autodesk Maya}

a) Modelado en 3D de los elementos que aparecerán en la composición.

b) Realizar la composición mediante las cámaras en el software de animación 3D "Autodesk Maya".

c) Renderizar las imágenes finales que aparecerán en cada actividad.

d) Importar el banco de imágenes a Adobe Flash y hacer la programación correspondiente a los botones que aparecerán en pantalla.

e) Hacer correcciones mediante la retroalimentación recibida de los coordinadores de desarrollo.

f) Exportar la aplicación $s w f$ final.

\subsection{Validación del proceso de diseño}

Como parte de la metodología, tras terminar el proceso de diseño se procedió a la validación del mismo por medio de un primer test de mercado desarrollado ex professo y aplicado a un grupo de control. Con los resultados estadísticos se llevaron a cabo correcciones donde fue necesario, pasando entonces a una segunda valoración estadística donde se mostraron los elementos del diseño del proyecto a un segundo grupo de personas, los resultados permiten entonces realizar correcciones finales de ser necesarias, permitiéndonos pasar entonces de la fase de "Diseño y Desarrollo" a la de "Producción e Implementación" [5].

\section{Desarrollo}

Investigación Preliminar: Análisis del contexto y recogida de datos sobre el entorno del producto.

Se procedió al establecimiento de la segmentación de mercado, paso importante que nos permite verificar la efectividad del diseño de los elementos implícitos en la creación de la plataforma, al delimitar los usuarios potenciales de la misma. Esta información será útil para definir el rumbo del desarrollo, específicamente del aspecto visual.

\section{Segmentación del Mercado. Usuarios potenciales de la plataforma}

1. Variable demográfica

Edad: 12 años en adelante.

Sexo: Indistinto.

Estado civil: indistinto.

2. Variable socio-económica.

Nivel de estudios: Básico.

Ocupación: Indistinto.

Nivel económico: Indistinto.

3. Variable psicográfica.

Personalidad: interesados por aprender herramientas para la vida, así como Información de salud y prevención.

Intereses: aprendizaje y superación personal.

Valores: responsabilidad, respeto, perseverancia y tolerancia.

4. Variable geográfica.

Los usuarios de las clínicas del sector público a nivel regional (la comarca lagunera). Posteriormente a nivel nacional.

5. Objetivo.

Obtener información clave del usuario final acerca del producto desarrollado por Compax.

6. Usuarios potenciales.

Derechohabientes al sistema de salud público interesados en aprender herramientas por medio de la computadora. 


\section{Establecimiento de la muestra}

Para la actual investigación, se seleccionaron 20 personas adultas de sexo indistinto. Se estableció que la variable referente a la disponibilidad de servicio médico público no fuera determinante para obtener datos útiles al estudio.

\section{Descripción de los instrumentos a utilizar}

Se utilizaron los medios electrónicos como internet y las redes sociales, así como la herramienta Google Forms, la cual fue muy útil para construir la encuesta y enviarla a los encuestados. Dicho instrumento estadístico fue aplicado tras el desarrollo grafico inicial de personajes, logos y demás iconos.

\section{Diseño de personajes}

Los personajes se crearon con la finalidad de aparecer en los contenidos, ilustrando situaciones y contextos. Para esta plataforma el cliente solicitó al Departamento de Desarrollo de Software el diseño de personajes caricaturizados y de diversos oficios, en este caso promotores, trabajadores sociales, psicólogos, profesores, técnicos y padres e hijos de familia. Las bases para desarrollo y diseño de personajes toman en cuenta no solo los aspectos estéticos, sino el reflejo de la psicología de los mismos. Tal y como menciona Bryan Tillman, director de diseño y arte de videojuegos del Instituto de Arte de Washington, D.C. , el aspecto estético será lo primero que notara el espectador/usuario en cuanto al diseño del personaje se refiere, por lo que debe realizarse tomando en cuenta no solo el estilo personal del creativo, sino las preferencias del segmento objetivo, respondiendo al menos a dos importantes cuestiones: 1. ¿Cuál es el grupo de edad al cual te diriges con tu personaje? 2. ¿En qué genero va a aparecer tu personaje? [6] Tillman segmenta las características de diseño de personajes de acuerdo, en principio, a la edad del usuario. Tras el estudio de las variables demográficas y psicográficas, estas fueron consideradas en el diseño de los personajes.

\section{Dicho proceso es el siguiente:}

a) Buscar referencias para la creación de personajes, como ropa o peinados.

b) Llevar a cabo bocetos y trabajarlos hasta al alcanzar el aspecto deseado

A)
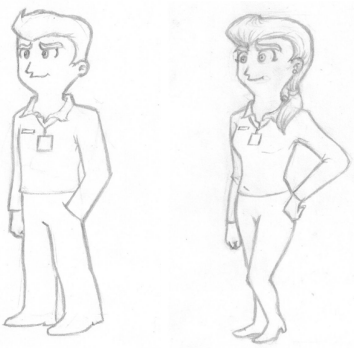

B)
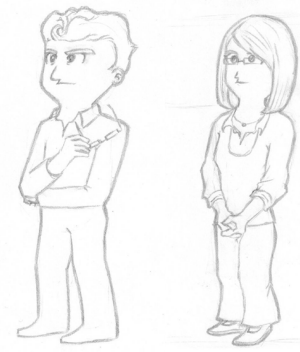

C)
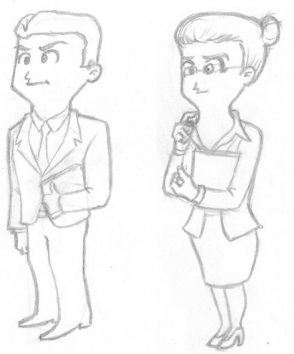

F)

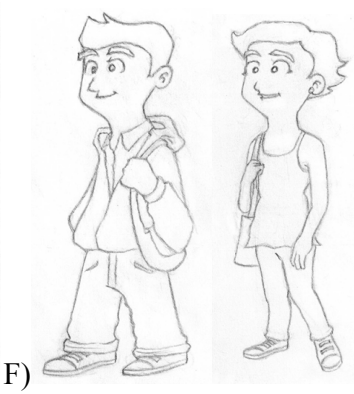

Figura 1. A continuación se presentan los bocetos finales de la primera etapa de Diseño de Personajes, Los cuales corresponden a: A) Promotores, B) Psicólogos, C) Trabajadores Sociales, D) Trabajadores, E) Padres de Familia y F) Hijos de Familia. Cabe señalar que durante el proceso de exploran varias líneas y conceptos diferentes antes de finalmente decantarse con algún diseño para la implementación del prototipo.

c) Digitalizar los bocetos de manera vectorial en Adobe illustrator. Para este proceso se dibujó encima de los bocetos escaneados utilizando la herramienta "pluma", puesto que la herramienta de vectorización automática no dio resultados satisfactorios. 


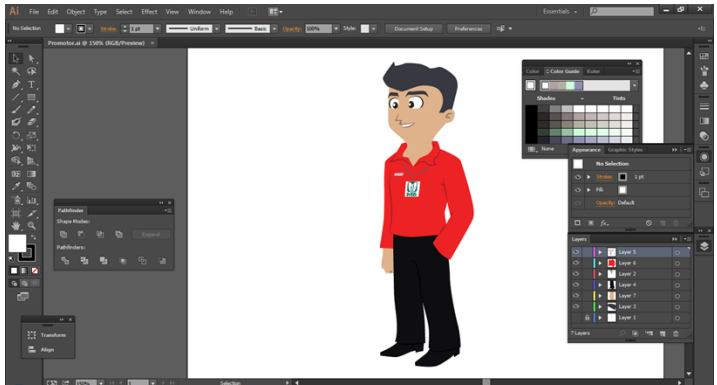

Figura 2. Digitalización de los bocetos mediante programas de diseño vectorial

d) Hacer correcciones mediante la retroalimentación recibida de los coordinadores de desarrollo. En la mayoría de los casos se hicieron ajustes de color para que fueran compatibles con la paleta final del software, además se cambiaron ciertos detalles de proporción, vestimenta y expresiones faciales.

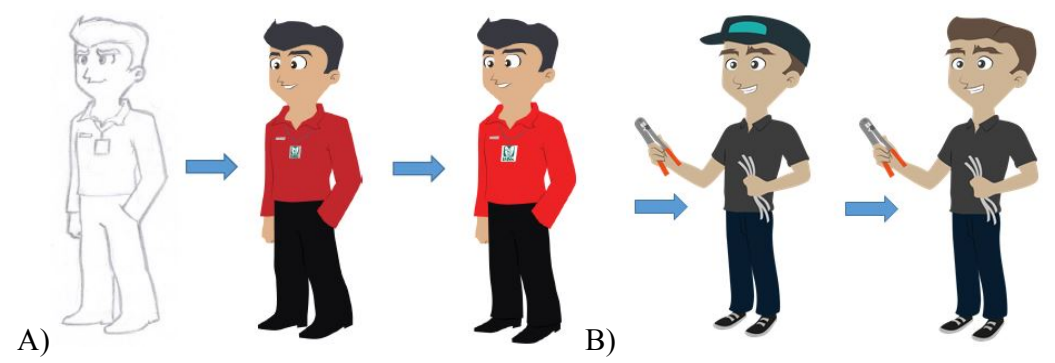

Figura 3. Ejemplos del proceso de corrección y digitalización de personajes. La fig. A) muestra la evolución del personaje profesor. El ejemplo B) Este personaje es una variante del profesor, por lo que no cuenta con boceto pues surgió directamente en digital.
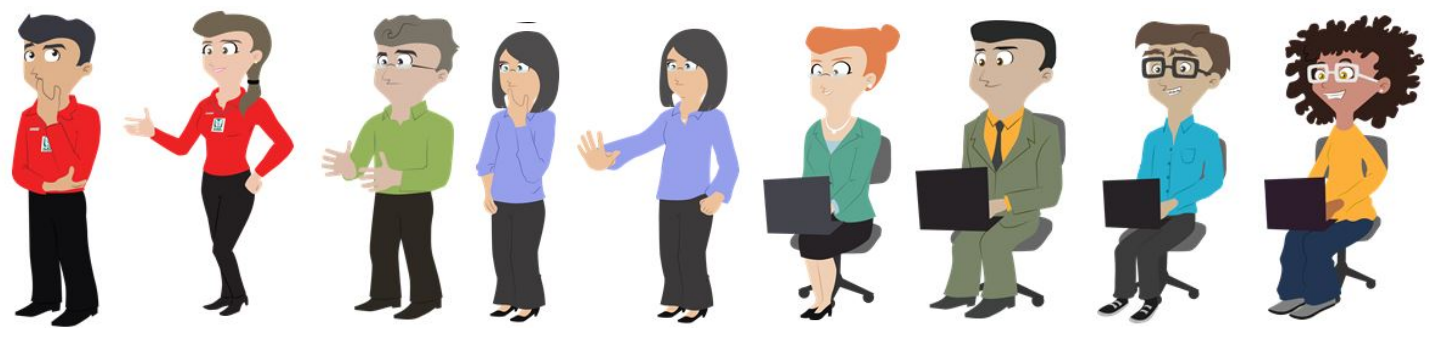

Figura 4. Se diseñaron además otras posiciones de los personajes para ilustrar diferentes situaciones, cabe señalar que los diseños mostrados en esta imagen son los finales. La segunda encuesta fue llevada a cabo empleando estos mismos diseños pero con otras poses.

e) Por último, se entrega las imágenes finales a los programadores para que puedan incrustarlas en el código del software.

\section{Banco de imágenes}

El siguiente paso en nuestro flujo de trabajo consiste en diseñar el Banco de Imágenes a emplearse en el sitio web. Cabe señalar que solo uno de los autores del presente artículo es verdaderamente un Diseñador Gráfico, por lo que su asesoría y la de los diseñadores asignados al proyecto fué invaluable. Los consejos de la Agencia Británica de Diseño e identidad corporativa Big Cat Group reflejan las bases en las que se fundamenta el diseño de Logotipos e Imagotipos; Simple: un logo simple facilita la recordación y la pregnancia, es decir que la gente lo capte e identifique más fácil. La mayoría de los mejores logos del mundo son sencillos, no tienen muchos colores y tampoco incluyen figuras complejas. Memorable: los buenos logos deben permanecer en la mente del cliente, este punto está aliado con el anterior, pues entre más sencillo sea una imagen más fácil será guardarla en la mente. Atemporal: un buen logotipo debe trascender en el tiempo y perdurar durante varios años, es posible que se le realicen cambios mínimos a lo largo de su historia, pero debe mantener su misma esencia, de lo contrario los receptores se confundirán y no podrán recordar una imagen que cambia todo el tiempo. Versátil: al crear un logo es necesario pensar que debe adecuarse a un amplio número de medios y aplicaciones, desde una pluma hasta un espectacular, y en todos debe verse bien. Apropiado: el logo debe ser diseñado de acuerdo al 
target para el que va dirigido, usando los colores, las formas y las texturas adecuadas para generar empatía en el público objetivo [7]. En el caso del logotipo del cliente (el cual se debe mantenerse en reserva) este aparece como parte del menú de inicio y para el cual se diseñaron diversas propuestas, así como el diseño de Iconos.

\section{Diseño de iconos.}

Los íconos corresponden al conjunto de botones de acceso a los diversos contenidos educativos y los diversos gráficos que ilustran menús específicos.

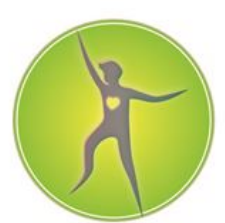

Vida saludable

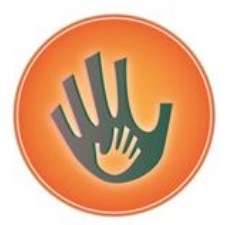

Mejores padres...Mejores hijos

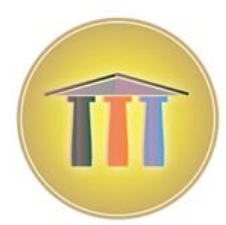

Vive con valores

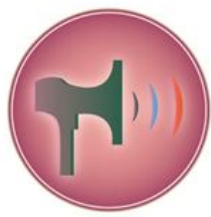

Formación de promotores

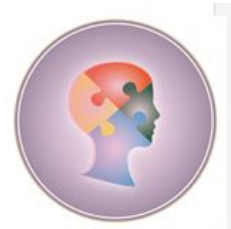

Material de Centros de Integración Juvenil

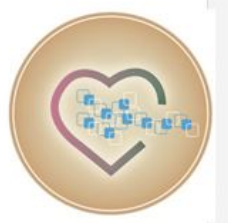

Proyecto Online

Figura 5. Los Iconos son diseñados en programas de dibujo vectorial. Aquí se muestran diseños preliminares.

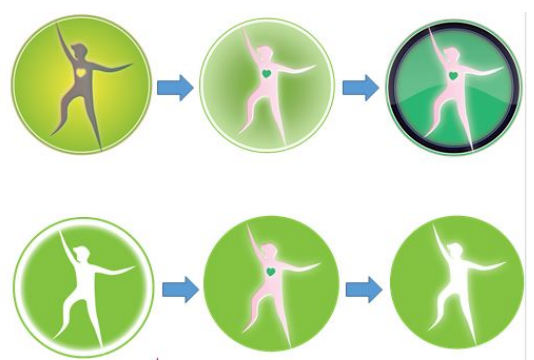

Figura 6. Tras la retroalimentación recibida de los coordinadores de desarrollo, se optó por un diseño más simplista, sin adornos como contornos, sombras ni luces de ningún tipo, así como el empleo de color brillante y llamativo posible. El ícono de vida saludable se toma como ejemplo para explicar el proceso de cambio en el diseño.

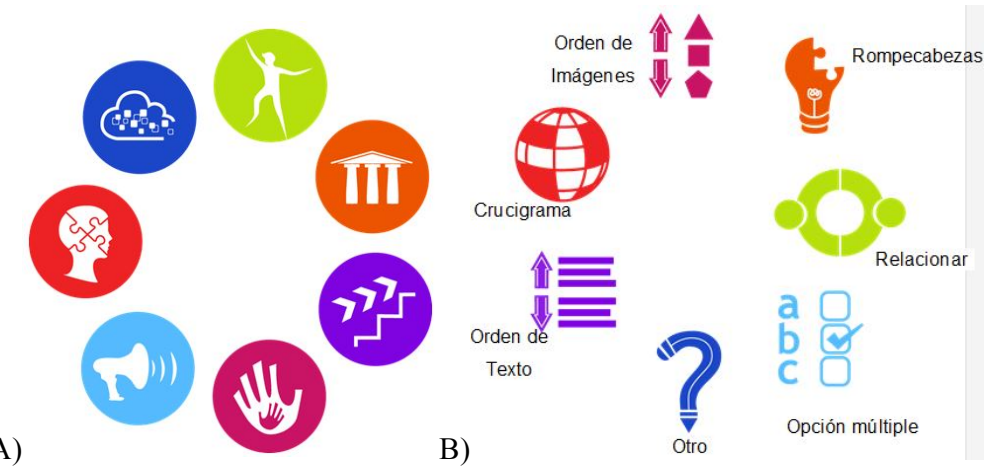

Fig. 7. A) Imágenes finales de los iconos, los cuales son entregados a los programadores para que puedan incrustarlas en el código del software. B) El mismo proceso se llevó a cabo para el diseño de los Iconos Adicionales. 


\section{Diseño y animación de mascota.}

La metodología empleada es similar al de diseño de personajes. a) Buscar referencias para la creación de personajes, como ropa o peinados. b) Llevar a cabo bocetos y trabajarlos hasta al alcanzar el aspecto deseado. Digitalizar los bocetos de manera vectorial en un programa de animación digital 2D como el Toon Boom. Tras terminar el paso del arte conceptual, se procedió a la animación de este y los demás personajes, a este proceso se le denomina Rigging. Una vez que se tiene el control básico sobre las articulaciones del personaje, se procede al control más fino, en este caso de los "labios", dicho proceso es denominado en la Industria como lip-sync o sincronización de labios, este servirá para poder hacer las coincidencias entre el audio-dialogo y la animación. La última fase es la generación digital del personaje en alta calidad, el Render.[8] [9]
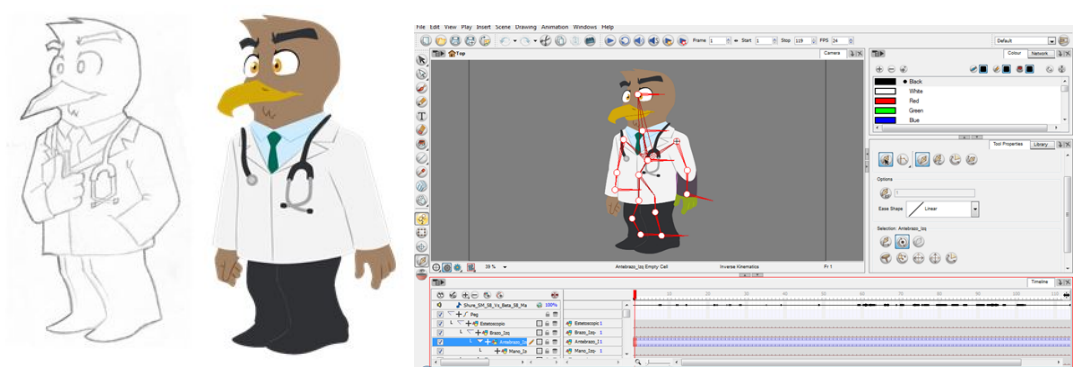

Figura 8. A) Boceto de la mascota. Tras digitalizar los bocetos de manera vectorial en el programa de animación 2D Toon Boom, se realizaron correcciones de algunos detalles como el pico. B) el sig. paso consistió en la creación del esqueleto de este y los demás personajes con la herramienta Joint e inverse kinematics[8][9], del software de Animación Digital 2D ToonBoom. A este procedimiento se le denomina: Rigging. [8] [9]

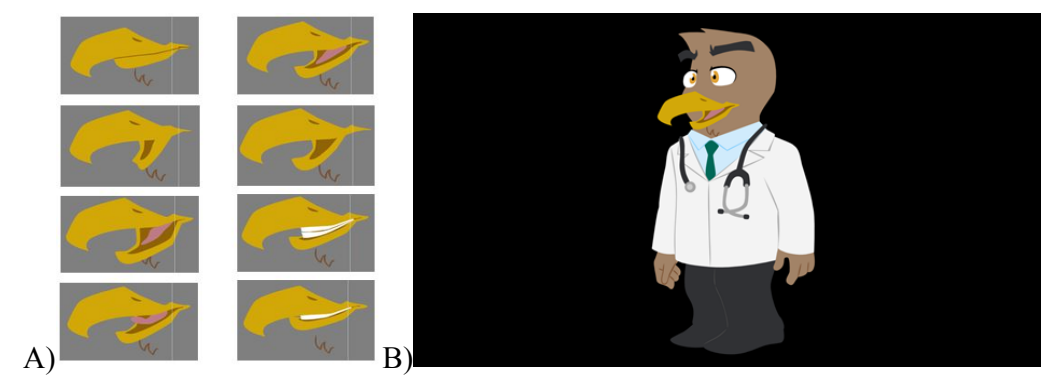

Figura 9. A) Realizar la animación correspondiente con la herramienta Lip-Sync. Para esto se dibujó cada boca, que expresa un fonema, por separado. B) Render final del personaje, tras las correcciones recibidas realizadas por parte de los coordinadores de desarrollo.

\section{Análisis estadístico. Validación del proceso de diseño conceptual.}

Resultados del primer instrumento encuestador, el cual es importante para medir el nivel de aceptación del diseño proyecto, además de conocer su potencial impacto en el contexto social y cultural del usuario de la plataforma, preparándolo a su vez para las preguntas relacionadas con el diseño de logos y personajes.

¿Cuentas con servicio médico de cualquier tipo?

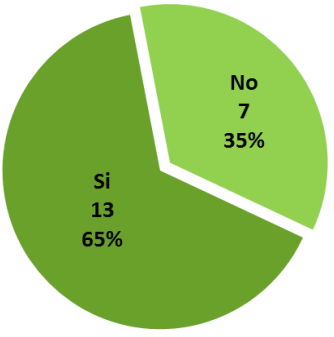

¿Qué tanta información se te brinda sobre aspectos de salud, valores y prevención la clínica a la que acudes?
¿Con qué frecuencia utilizas la computadora?

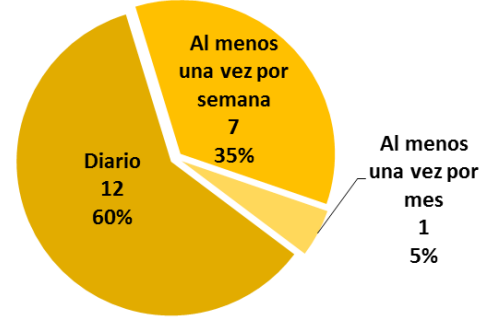

¿Qué tan importante consideras recibir información de temas de salud, valores y prevención? 

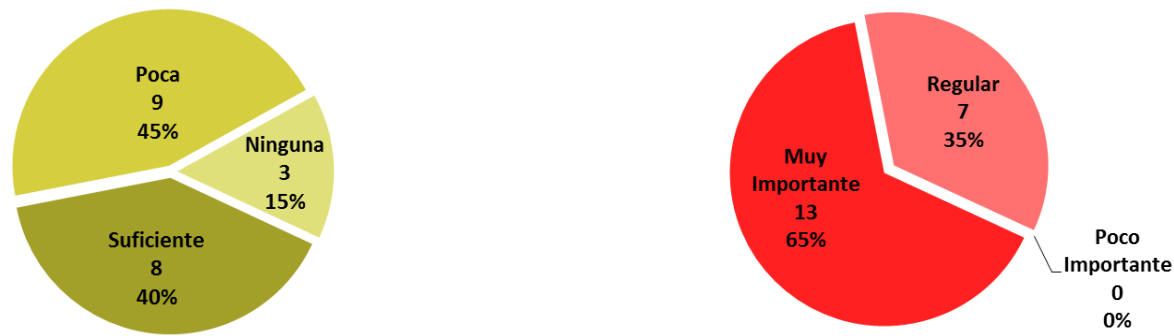

Figura 10 Gráficas que denotan un concentrado de los resultados obtenidos en las encuestas aplicadas para las primeras cuatro interrogantes en el instrumento de evaluación considerado para el análisis descrito.

En la Figura 10 los resultados muestran que el $65 \%$ de los encuestados cuentan con servicio médico de algún tipo, mientras el $35 \%$ restante no, lo cual es desafortunadamente bastante significativo de la realidad social de nuestro país. Dado que la encuesta fue realizada por internet, la mayoría de las personas resultó ser usuarios casuales de una computadora, siendo en un principio el target del que nos gustaría conocer sus impresiones, para posteriormente pasar a implementar el proyecto en "aulas" equipadas en las instalaciones del cliente, de tal forma que se no quedara solo en este segmento su implementación. La gran mayoría consideró muy importante recibir información de salud, lo cual es un buen inicio para la justificación del proyecto. Es interesante señalar como entre estos usuarios regulares de una computadora surgió un empate técnico entre los que expresaron que era suficiente y poca información la recibida; sin embargo, la mayoría mostró su postura en cuanto a la importancia de estar informado, lo cual indica que el potencial de aprovechamiento del producto, en especial al observar el resultado a la pregunta cinco (fig.11) pues los encuestados opinan estar de acuerdo en emplear una computadora para ampliar su información en esta área.

¿Utilizarías la computadora para aprender mas acerca de estos temas?

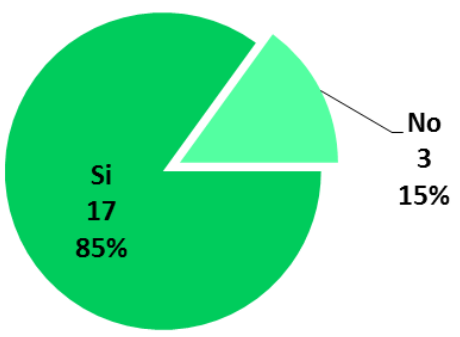

¿Cómo calificarías el diseño de la siguiente mascota?
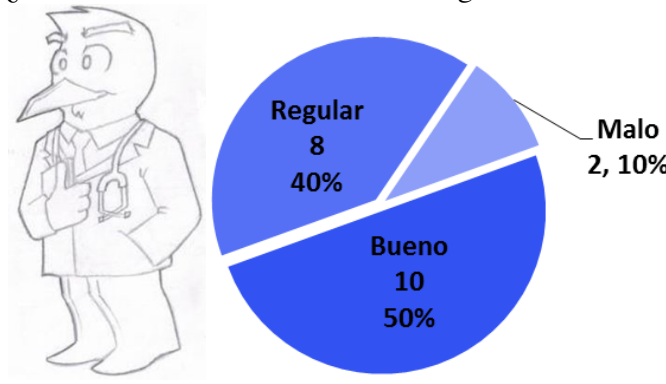

¿Cuál de los siguientes logotipos consideras ser más de su agrado? (Se muestran variantes del logo del cliente)

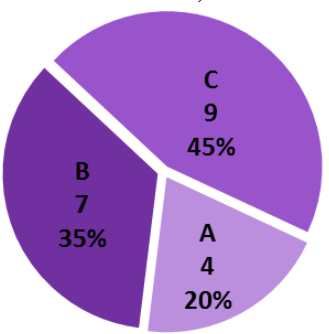

¿Cómo calificarías el diseño del siguiente personaje?

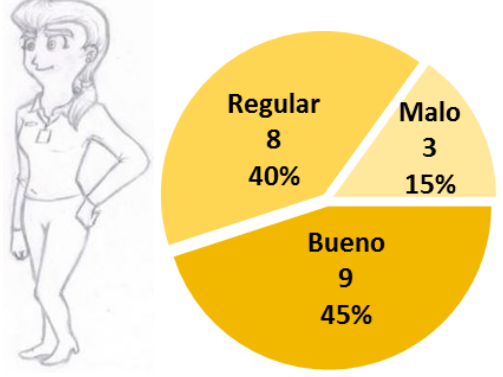

Figura 11. Gráficas con el resultado de las encuestas aplicadas para las preguntas descritas en el instrumento de evaluación considerado para el análisis.

En lo referente a la practicidad del diseño de logos y caracterización de personajes, la mayoría se inclinó por el tercer logo, el cual, a su vez, fue entonces elegido por el equipo de desarrollo para su implementación en la página web, cabe aclarar que por acuerdo de confidencialidad con el cliente no es posible mostrar esta variantes de su logo institucional, sin embargo mostramos los resultados para validar el desarrollo de proyecto mediante la metodología empleada. En lo cuanto al estilo empleado para diseñar los personajes, las opiniones resultaron muy divididas, pues si bien es cierto que en ambos casos los personajes mostrados fueron aprobados por casi la mitad de los encuestados, una considerable considero su diseño "Regular". Esto indica que se requiere trabajar 
más al personaje. Dichas opiniones se tomaron durante la segunda fase de diseño tratando de no cambiar radicalmente el concepto que ya se tenía de los personajes.

Segunda fase de diseño. Pantalla splash y Escenarios 3d.

Se diseñaron los elementos que aparecerán en la composición de la pantalla splash e importarlos. En este caso se utilizaron las formas presentes en los íconos del menú de inicio, para posteriormente realizar la animación correspondiente con ayuda de las curvas de animación en After Effects. Debe tener una duración máxima de 4 segundos. Se procede entonces a las correcciones mediante la retroalimentación recibida de los coordinadores de desarrollo. En este caso la retroalimentación sirvió mucho para mejorar la fluidez de la pantalla splash. Cabe mencionar que el autor principal fue solo uno de varios modeladores/animadores que trabajaron a su vez aspectos de Fx visual en After Effects para las diversas pantallas splash.

A)

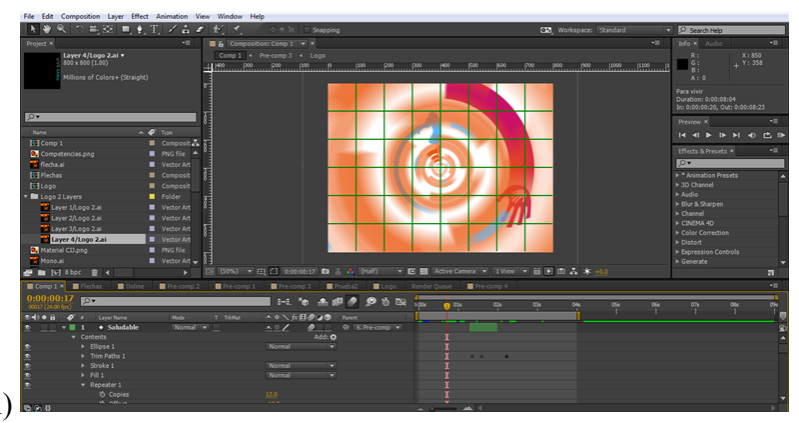

B)

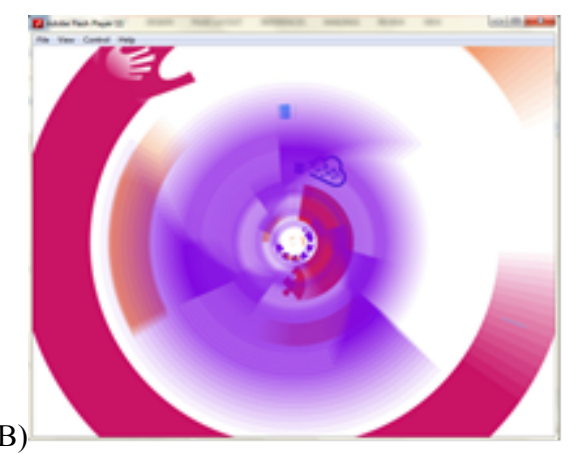

Figura 12. A) Curvas de animación de pantalla Splash realizado en After Effects. B) Render final de la pantalla splash.

\section{Diseño de Escenarios 3d.}

Una vez terminado las bases del arte conceptual, diseño de logos y las bases para su animación 2D, se procede al modelado en 3D de los elementos que aparecerán en la composición como escenario digitales, dentro de las actividades interactivas. Es interesante señalar que pese a realizarse todo el modelado en Autodesk Maya, se le dio un tratamiento conceptual de forma tal que pareciese animación 2D. Esto con la finalidad de integrar ambos elementos del diseño de forma armoniosa y estética. Posteriormente se Realiza la composición de le escena y animación mediante las cámaras en Autodesk Maya. El siguiente paso consistió en el renderizado de las imágenes finales que aparecerán en cada actividad, para posteriormente importa el Banco de imágenes a Adobe Flash y hacer la programación correspondiente a los botones que aparecerán en pantalla. Tras sus correcciones, exportar el archivo ejecutable swf final.

A)

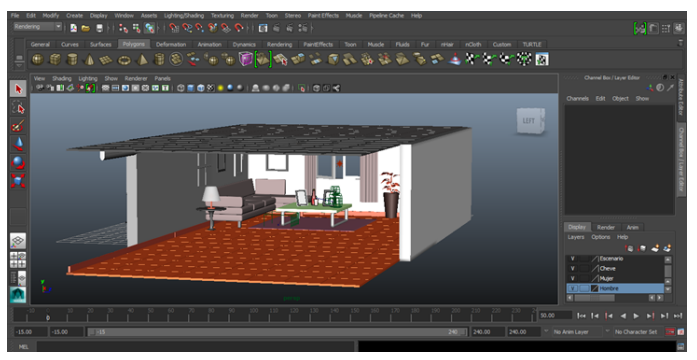

Figura 13. A) Modelado de escenarios 3D.

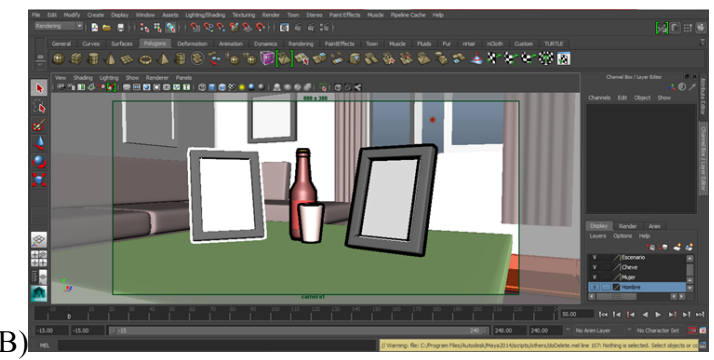

B) inclusión de dichos escenarios en la pag. Web

Validación del proceso de Diseño: Encuesta de resultados.

Tras emplear los resultados del primer instrumento estadístico en la corrección del prototipo, se pasó a la validación del trabajo de diseño.

El objetivo es mostrar lo que el mercado piensa del producto final. En esa encuesta se pregunta al segmento objetivo en que porcentaje los "atributos" señalados en el instrumento encuestador reflejan las condiciones del diseño del producto, tanto de los logos, como de los personajes y la pagina "splash". 


\section{Descripción de los instrumentos a utilizar}

Se utilizaron los medios electrónicos como internet y las redes sociales, así como la herramienta Google Forms, la cual fue muy útil para construir la encuesta y enviarla a los encuestados.

\section{Establecimiento de la muestra}

Nuevamente, para este segundo estudio, se seleccionaron 20 personas adultas de sexo indistinto. En el anterior ejercicio estadístico se recabaron algunas opiniones acerca de diseños preliminares; en esta ocasión se pretende mostrar las versiones finales para de esta forma obtener valiosa retroalimentación e identificar puntos débiles. Tomando en cuenta que la plataforma se trata de una página web, se consideró prudente realizar preguntas relacionadas al uso de internet.

\section{Análisis de resultados.}

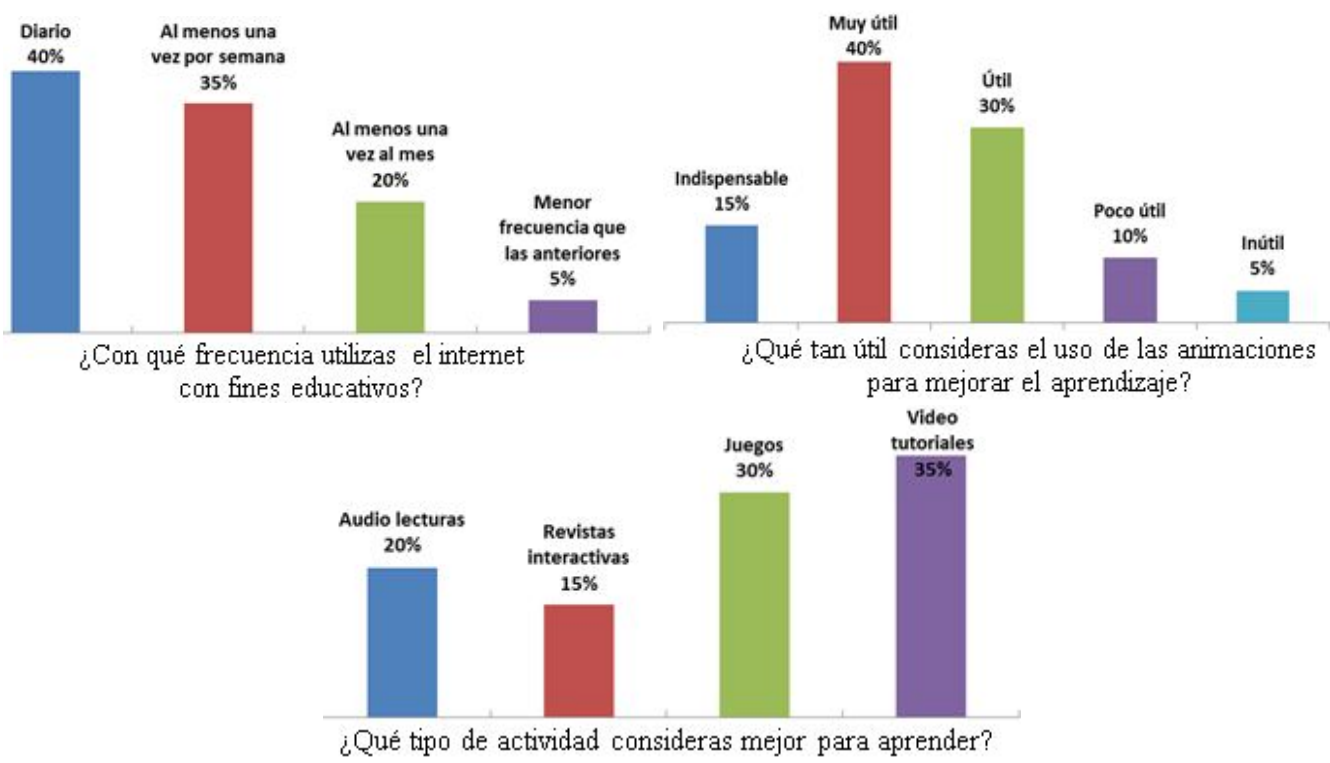

Figura 14. Gráficas con el resultado de las encuestas aplicadas para preguntas planteadas en el instrumento de evaluación.

Para la pregunta: ¿Con qué frecuencia utilizas el internet con fines educativos?, se encontró con una mayoría de usuarios ávidos de internet. Esto representa un dato positivo para el estudio, ya que se espera que una parte de los usuarios pueda acceder a la plataforma en línea. En la interrogante: ¿Qué tan útil consideras el uso de las animaciones para mejorar el aprendizaje?, La mayoría mostró una respuesta afirmativa. Los encuestados consideraron para la pregunta: ¿Qué tipo de actividad consideras mejor para aprender?, que es importante el empleo de video tutoriales. Esta pregunta fue útil para establecer la dirección futura de los contenidos en línea de la plataforma, la cual cuenta con actividades interactivas animadas en Flash.

Para la segunda parte del instrumento encuestador, se optó por una opinión construida por medio de opciones múltiples, redactadas en base a "atributos" del diseño. Fue posible elegir una o más opciones, de modo que el encuestado aportara una respuesta más amplia, por ello la suma de los porcentajes no da un 100\%. Pues la intención del instrumento es medir la impresión del encuestado en relación al diseño. La primera de las interrogantes relacionadas con el diseño se hace en relación a los iconos mostrados en la fig. 7: Limpieza/estética $(30 \%)$, atractivo visual/interesante $(50 \%)$, es entendible $(25 \%)$, original $(15 \%)$, mediocre $(0 \%)$ y otro $(0 \%)$. Cabe aclarar que el atributo de 'es entendible' se refiere a la identificación o asociación hacia el concepto o idea que representan. Observándose que la evaluación más alta la obtiene el atributo referente al atractivo visual, es decir, los íconos lograron un grado de interés considerable, mientras que la limpieza o estética obtuvieron el segundo mayor porcentaje de calificación, entendiéndose entonces que el público dio crédito a la técnica empleada y que la considera "estética". Sin embargo se observa una baja evaluación en los atributos de es entendible y original, por lo que se desprende la posibilidad de una difícil interpretación de su significado o asociación hacia el concepto que representaban. 


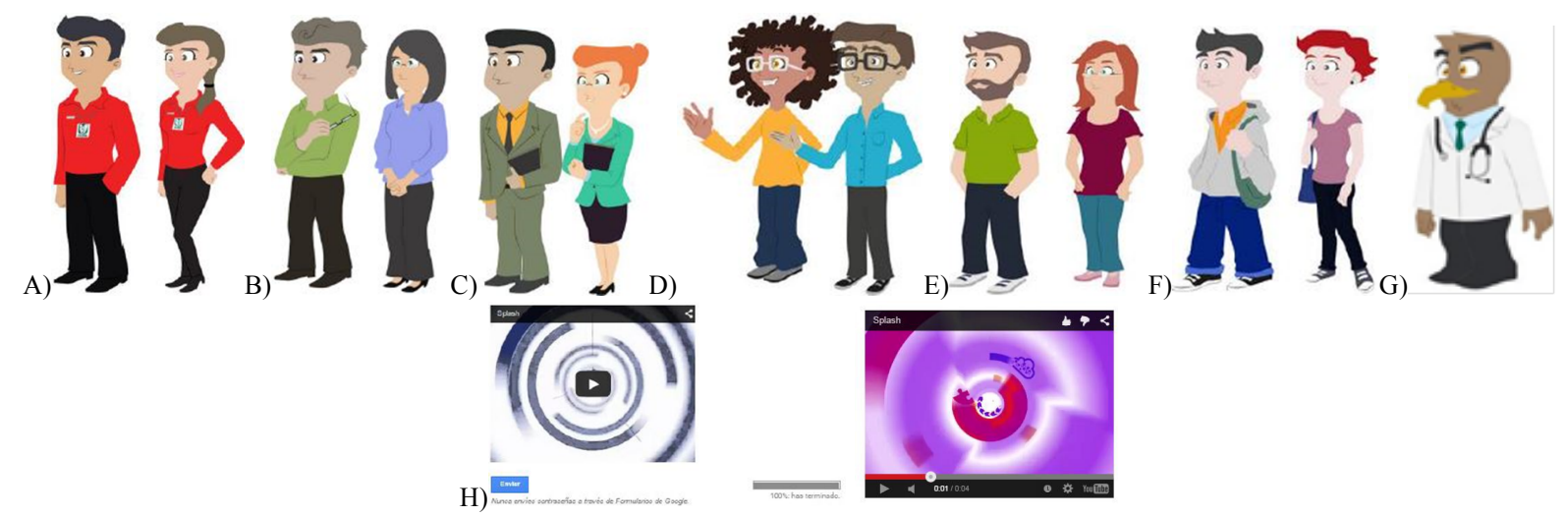

Figura 15. Ilustraciones finales empleadas en el intrumento encuestador en linea A) Promotores. B) Psicologos. C) Trabajadores sociales. D) Profesores. E) Padres de Familia. F) Hijos d e Familia. G) Familia. H) Pagina "Splash".

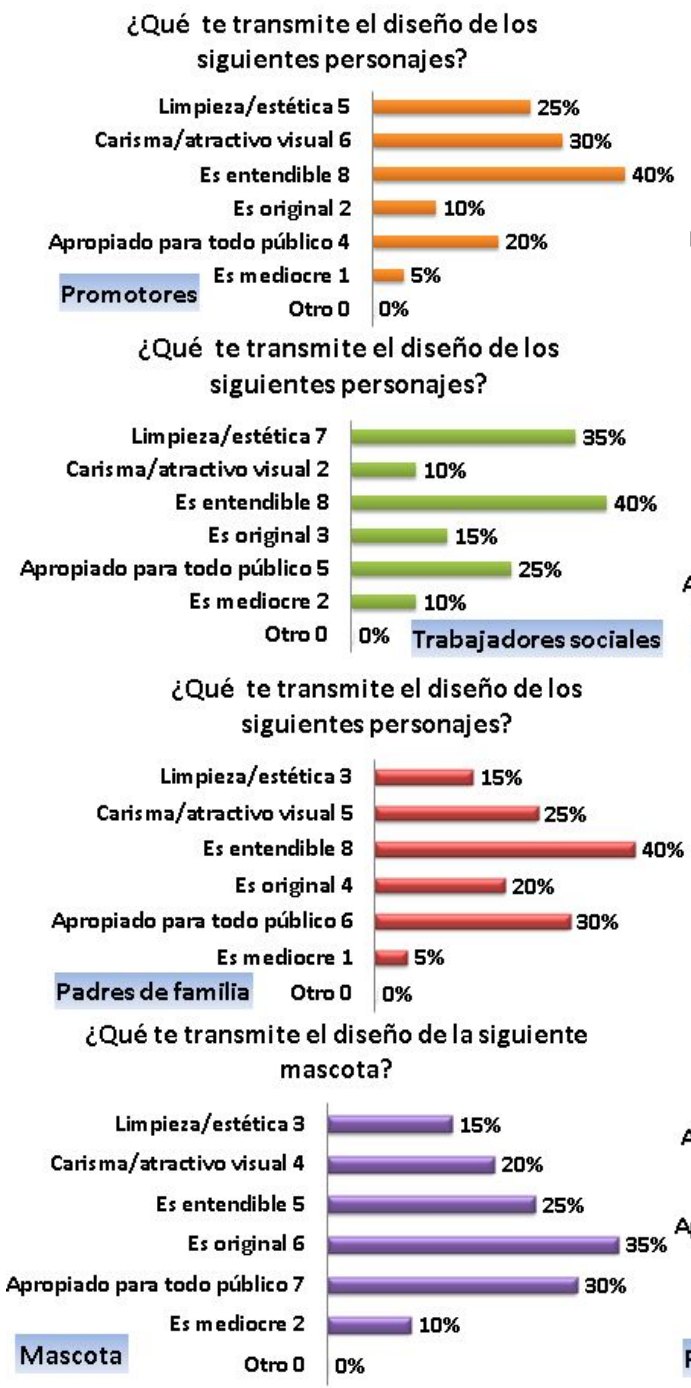

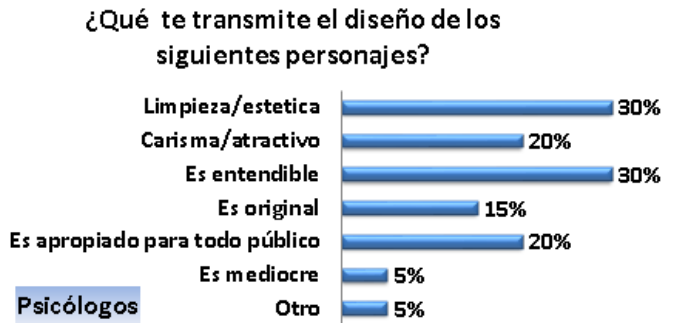

¿Qué te transmite el diseño de los siguientes personajes?

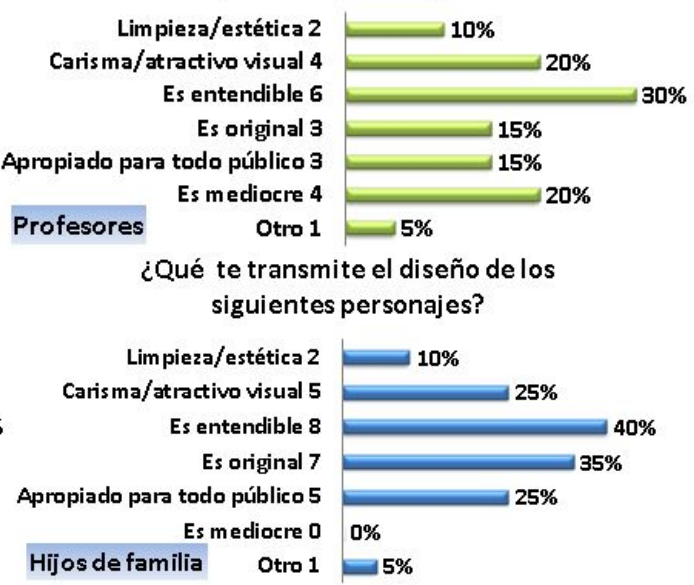

¿Qué te transmite la siguiente animación?

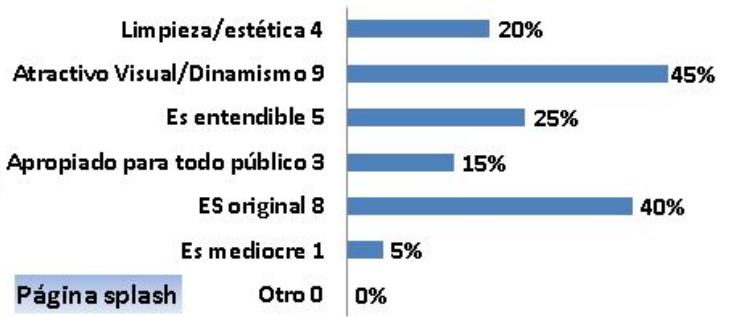

Figura 16. Gráfica que representa la evaluacion obtenida de los atributos de los personajes y la animacion de la Pagina splash.

En el apartado referente al diseño de personajes con la pregunta ¿Qué te transmite el diseño de los personajes?

Podemos observar que el diseño de personajes obtiene en términos generales una buena aceptación, lo cual se denota en el atributo con la evaluación más alta Es entendible el cual siempre se mantiene de un $30 \%$ a un $40 \%$ (solo la Mascota baja a 25\%), interpretándose como personajes asociados al concepto que se pretende 
representar, es decir un profesor, un padre de familia, etc. El siguiente atributo que se mantiene consistentemente alto es Carisma/atractivo visual con una evaluación de un $20 \%$ hasta un $30 \%$ lo cual denota un saludable nivel de empatía. El resto de los atributos varían en su evaluación de un personaje a otro, Originalidad por ejemplo aparece muy alto en el diseño de Hijos de familia y Mascota (ambos 35\%), mas sin embargo muy bajo en el resto de los caracteres siendo los Promotores el diseño considerado como el menos original con un 10\%. Lo mismo sucede con el atributo Limpieza/estética donde se tienen resultados que van desde un 10\% (Profesores) hasta un 35\% (Trabajadores sociales). Analizando este resultado, se desprende la posibilidad de que algunos encuestados confundieran la estética en cuanto a la técnica del dibujo con la estética del atuendo del personaje. Siendo esto entendible desde el punto de vista grafico pues los personajes fueron realizados con la misma técnica, sin embargo, los que tienen vestimenta más formal obtuvieron un mejor puntaje en dicho apartado, como es este caso. Un detalle importante a considerar en futuras encuestas y en el proceso de diseño. Este tipo de opiniones son muy importantes para mejorar el impacto del producto en el segmento objetivo así como el nivel de empatía. Por otro lado, a pesar de obtener calificaciones buenas en general, algunos personajes obtuvieron una cantidad considerable de puntos en el aspecto de mediocre, lo cual muestra un área de oportunidad importante.

El trabajo en el diseño de la página splash (fig. 15H) fue particularmente intenso para lograr un efecto dinámico, por tratarse de la animación introductoria al software. Afortunadamente, los resultados fueron favorecedores en este aspecto pues dicho atributo muestra un $45 \%$ de aceptación, así como en el de originalidad (40\%), quizá de los más difíciles de lograr en todo diseño. Sin embargo, hubo calificación baja en cuanto a ser apropiada para todo público (15\%), esto puede deberse a la densidad de movimientos mostrados durante la transición de imágenes, volviéndola difícil de apreciar. Este fue el precio a pagar por la restricción de cuatro segundos de duración que debía cumplir.

\section{Conclusiones y trabajos futuros}

Los resultados mostraron gran aceptación entre el público y el equipo de desarrollo del proyecto con áreas de oportunidad ya indicadas en el texto, que sin embargo representan un bajo porcentaje de los resultados del instrumento estadístico, siendo la principal aportación del presente trabajo en la aplicación de las herramientas metodológicas y sistémicas con las cuales abordar el diseño de proyectos tecnológicos más media, dejando de lado consideraciones solo de tipo cualitativo (situación que es lo común en el área de diseño), tratando de medir variantes cuantitativas que permitan evaluar el impacto del producto final en el sector objetivo siendo de particular importancia por tratarse los primeros trabajos llevados a cabo en una industria emergente como lo es el sector de la Animación Digital, donde aspectos como "arte conceptual" y "Psicología y creación de personajes" son áreas que los nuevos ingenieros en Animación pretenden atacar sistémicamente.

Al momento de redactar el presente artículo, los resultados de este proyecto se encuentran siendo revisados y considerados para la corrección del proyecto y su posterior implementación, la cual está pendiente de aprobación por parte del cliente. Encontrándose en fase de prueba, por lo que su funcionamiento se sigue monitoreando. Como todo sistema informático, requiere de periódicas revisiones. Además, se trabaja en la adición constante de nuevos contenidos educativos, todo de acuerdo al contrato con el cliente.

Agradecimientos. Los autores desean agradecer a la empresa COMPAX, en particular a: Lic. Perla E. Parada Morado, Gerente de Soluciones; Lic. Dulce María Aguilera, Coordinadora Académica y Lic. Tatiana Aguilera, Departamento de Desarrollo, por permitir citar su trabajo así como por su apoyo en la redacción de este artículo de divulgación científica.

\section{Referencias}

1. Jiménez, C. A. La Inteligencia Lúdica Bogotá. Colombia: Cooperativa Editorial Magisterio. pp 130-149 (2005).

2. Garrido, M.F. TESIS DOCTORAL Formación basada en las Tecnologías de la Información y Comunicación: Análisis didáctico del proceso de enseñanza-aprendizaje. Universidad Rovira i Virgili de Tarragona. Pp. 156-185 (2003)

3. Editorial Team of EdTechReview. Role of Animation in Student's Learning. EdTechReview. Retrieved from http://edtechreview.in/trends-insights/insights/367-role-of-animation-in-students-learning. (2013). Accedido el 12 de Agosto de 2015

4. México destaca a nivel mundial en las industrias creativa. TRADE LINKS. LAZOS COMERCIALES Año7, N11. Publicada por la Misión de México ante la UE Oficina de Representación de la Secretaría de Economía. http://www.economiasnci.gob.mx/sic_php/pages/bruselas/trade_links/esp/novesp2009.pdf (2009). Accedido el 12 de Agosto de 2015

5. Ivañez, J.M. Cap.6 El diseño de productos. Peralba, M.V. La Gestión del Diseño en la Empresa. Ed.McGraw-Hill, pp $123-158,147-148,124,142-146(2000)$ 
6. Tillman, B. Creative Character Design. Focal Press. pp 105 (2011)

7. Jaen, G. 5 Puntos básicos para diseñar un buen logo. InformaBTL. http://www.informabtl.com/2013/03/27/5-puntosbasicos-para-disenar-un-bueno-logo/. (2013). Accedido el 25 de Agosto de 2014

8. Díaz, M.A. Cap.2 Desarrollo y Avances Tecnológicos en la Animación. Tesis Doctoral Análisis de los avances digitales para el desarrollo e integración de la animación tradicional y la animación generada por ordenador en películas históricas. pp 247, 244. (2010).

9. TOON BOOM HARMONY 12.1 - Essentials Edition - Fundamentals Guide. Toon Boom Documentation. http://docs.toonboom.com/download/harmony/12/ESS/HAR12_Essentials_Fundamentals_Guide.pdf. pp128-180 (2015) Accedido el 25 de Agosto 2015. 